\title{
Caracterização de bebida láctea pasteurizada com adição de ferro
}

\author{
Characterization of lactic drink pasteurized with added iron \\ Clarice dos Santos Sousa ${ }^{1}$, Bárbara Cruz Tavares de Macedo Fernandes ${ }^{2}$, Paulo Henrique S. Fernandes ${ }^{1}$.
}

Como citar esse artigo. Sousa CS, Fernandes BCTM, Fernandes PHS. Caracterização de bebida láctea pasteurizada com adição de ferro. Revista Teccen. 2015 Jan./Jun.; $08 \quad$ (1): 27-32.

\begin{abstract}
Resumo
A caracterização físico-química e microbiológica de uma bebida láctea pasteurizada com adição de ferro foi realizada com o intuito de avaliação de qualidade. Na análise físico-química a bebida apresentou $12,67^{\circ} \mathrm{D}$ de acidez; $2,07 \%$ de lipídeos; $1,16 \%$ de proteínas; $16,70 \%$ de carboidratos, $9,22 \%$ em extrato seco total; $7,15 \%$ de extrato seco desengordurado; $0,38 \%$ de cinzas; $79,69 \%$ de umidade; $90,04 \%$ de calorias e um pH de 6,53. Para a caracterização microbiológica foram realizadas análises de coliformes totais a $30^{\circ} \mathrm{C}$ e de mesófilos restritos que apresentaram resultados dentro do permitido pela legislação vigente. A concentração de ferro na bebida foi de $2,5 \mathrm{mg} / 100 \mathrm{ml}$, abaixo do ideal para a bebida ser considerada alimento enriquecido ou fortificado. $\mathrm{O}$ ferro é adicionado à bebida na forma de sulfato e grandes concentrações suas podem alterar as características sensoriais da bebida, tornando-a imprópria para comercialização.

Palavras-Chave: Análise físico-química. Análise microbiológica. Bebida láctea. Soro. Ferro.
\end{abstract}

\begin{abstract}
The physical-chemical and microbiological quality of pasteurized milk drink with added iron was performed in order to assess the quality of it.In physic-chemical analysis showed the beverage acidity $12.67^{\circ} \mathrm{D} ; 2.07 \%$ lipids, $1.16 \%$ protein, $16.70 \%$ carbohydrate, $9.22 \%$ in total solids, $7.15 \%$ extract nonfat dry, $0.38 \%$ ash, $79.69 \%$ moisture, $90.04 \%$ of calories and a $\mathrm{pH}$ of 6.53 . To characterize microbiological analyzes were performed Coliform bacteria at $30^{\circ} \mathrm{C}$ and results showed that mesophyll restricted to the extent permitted by law. The iron concentration in the beverage is $2.5 \mathrm{mg} / 100 \mathrm{ml}$, less than ideal so that the drink can be considered enriched or fortified food. The iron is added to the beverage in the sulfate form and high concentrations can even alter the sensory characteristics of the drink, making it unsuitable for marketing. Keywords: Physico-chemical analysis. Microbiological analysis. Drink milk. Serum. Iron.
\end{abstract}

\section{Introdução}

O leite, alimento indispensável aos mamíferos, é definido como produto secretado pelas glândulas mamárias e destinado às crias nos primeiros meses de vida, enquanto não podem digerir e assimilar outros nutrientes necessários à sua subsistência [Bhemer e Arruda 1999].

O leite para ser caracterizado como de boa qualidade deve apresentar as seguintes características sensoriais, nutricionais, físico-químicas e microbiológicas: sabor agradável, alto valor nutritivo, ausência de agentes patogênicos e contaminantes (antibióticos, pesticidas, adição de água, sujidades etc), reduzida contagem de células somáticas, e baixa carga microbiana, [Pereira Jr. et al. 2001]. A qualidade do leite e derivados é uma constante preocupação de técnicos e autoridades ligadas às áreas de saúde e laticínios, principalmente pelo risco de veiculação de microrganismos patogênicos e deteriorantes [Carmo 2001].

O soro de leite é o líquido residual obtido a partir da coagulação do leite destinado a fabricação de queijos [Brasil 2005]. É o principal subproduto da indústria de laticínios e em sua composição existe boa quantidade de excelentes nutrientes, dependendo do tipo e do processo de fabricação, sua composição é de aproximadamente $93 \%$ de água, $5 \%$ de lactose, $0,9 \%$ de proteínas, $0,3 \%$ de gordura e pequenas quantidades de vitaminas. Seu volume representa em torno de 85 a $95 \%$ do leite, retendo 55\% dos seus nutrientes [Mawson 1994], [BemHassan e Ghaly 1994], [Siso 1996].

Alguns autores salientam que $50 \%$ da produção mundial de soro é tratada e transformada em vários produtos alimentares, sendo quase a metade usada diretamente na forma líquida [Almeida et al. 2001]. Com o descarte de soro como resíduo, estima-se que a perda anual seja de aproximadamente 48 mil toneladas 
de proteínas, 24 mil toneladas de lactose, 33,6 mil toneladas de sais minerais, 14,4 mil toneladas de gordura e 5,76 toneladas de riboflavina [FAO 2007].

$\mathrm{O}$ soro de leite pode ser considerado um poluente extremamente problemático devido à sua elevada carga orgânica e grande volume gerado, devendo ser tratado antes de descartado, já que o soro bruto possui uma demanda bioquímica de oxigênio (DBO) de 30.000 a $60.000 \mathrm{mgL}^{-1}$, e a lactose é a responsável por aproximadamente $90 \%$ da carga orgânica do soro [Ghaly e Kamal 2004]. Além da poluição ambiental, o descarte do soro é também um desperdício de material proteico e de outros nutrientes [Almeida et al. 2001].

Devido ao alto custo de implantação e instalação de tratamentos biológicos para o soro, considerando o alto valor nutricional de suas proteínas e suas propriedades funcionais (solubilidade, estabilidade, formação de espuma, retenção de ar, emulsificação, retenção de água e formação de gel) é aconselhável o emprego de todas as alternativas viáveis para o aproveitamento do soro [Mosquim 1996].

No Brasil, a produção de bebida láctea é uma das principais opções de aproveitamento do soro de leite. As mais comercializadas são as bebidas fermentadas, com características sensoriais semelhantes ao iogurte e bebidas lácteas não fermentadas. O notável aumento no consumo de bebidas fermentadas verificado nos últimos anos em nosso país possibilita uma utilização racional de soro de queijo na elaboração desses produtos, com o aproveitamento desse subproduto de excelente valor nutricional [Santos et al. 2008]. Além disso, a bebida láctea pasteurizada é uma opção atrativa para as indústrias em função da simplicidade do seu processo de fabricação. Essa simplicidade ocorre devido à possibilidade de uso dos equipamentos já existentes na usina de beneficiamento de leite, o que gera redução no custo de fabricação [Pintado et al. 2001].

Entende-se por bebida láctea pasteurizada com adição, o produto lácteo resultante da mistura do leite (in natura, pasteurizado, esterilizado, UHT, reconstituído, concentrado, em pó, integral, semidesnatado ou parcialmente desnatado e desnatado) e soro de leite (líquido, concentrado e em pó) adicionado ou não de produto(s) ou substância(s) alimentícia(s), gordura vegetal, leite(s) fermentado(s), fermentos lácteos selecionados e outros produtos lácteos. A base láctea representa pelo menos 51\% massa/ massa $(\mathrm{m} / \mathrm{m})$ do total de ingredientes do produto, submetido à temperatura de Pasteurização Lenta de 62 a $65^{\circ} \mathrm{C}$ por 30 minutos e Pasteurização de curta duração de 72 a $75^{\circ} \mathrm{C}$, durante 15 a 20 segundos, em aparelhagem própria, resfriada entre 2 e $5^{\circ} \mathrm{C}$. Também deve estar presente na embalagem, a frase "BEBIDA LÁCTEA NÃO É LEITE" OU "ESTE PRODUTO NÃO É LEITE” [BRASIL 2005].

Neste tipo de bebida observa-se a redução da gordura saturada e do colesterol, em comparação com o leite integral. Basicamente, a diferença entre iogurte e bebida láctea é a consistência e redução do valor nutritivo do segundo, quando comparado ao primeiro produto. A bebida láctea é mais líquida, enquanto o iogurte é mais consistente [Simionato 2008].

A busca de alternativas para o combate à carência de ferro, que melhor se adaptem às condições de cada região, tem sido motivo de estudo, pois o ferro desempenha importantes funções no metabolismo humano como: transporte e armazenamento de oxigênio, reações de liberação de energia na cadeia de transporte de elétrons, conversão de ribose a desoxirribose, co-fator de algumas reações enzimáticas e inúmeras outras reações metabólicas essenciais [Torres et al. 1996]. Denomina-se anemia a diminuição anormal na concentração de hemoglobina no sangue [Organização Mundial de Saúde 1972], sendo esta considerada a principal consequência da deficiência de ferro. Em sua fase mais avançada, está associada a sintomas clínicos como fraqueza, diminuição da capacidade respiratória e tontura. Além disso, mesmo na ausência de anemia, a deficiência de ferro pode acarretar distúrbios neurocognitivos [Cook 1992].

Os produtos lácteos são apreciáveis fontes de proteínas, cálcio, vitaminas e outros nutrientes, porém são pobres em vitamina $\mathrm{C}$ e ferro. No entanto, a fortificação de leite com ferro é tecnicamente mais difícil em relação a outros nutrientes, porque as formas mais absorvidas são muito reativas e produzem efeitos indesejáveis quando acrescentadas ao leite. Compostos reativos de ferro catalisam reações oxidativas que resultam em sabor, odor e cor indesejáveis [Cook e Reusser 1983]. Faz-se necessário, portanto, para a obtenção de um produto que visa a características nutricionais importantes, a avaliação dos seus parâmetros físico-químicos e microbiológicos, de acordo com a legislação vigente, a Instrução Normativa 16, de 23 de agosto de 2005.

O presente trabalho teve como objetivo a caracterização físico-química e microbiológica de uma bebida láctea pasteurizada com adição de ferro, elaborada e comercializada por um laticínio da região, visando a avaliação conforme os parâmetros de qualidade estipulados pela legislação vigente, e comparando-a com outra bebida láctea com aspectos semelhantes.

\section{Materiais e Métodos}

A caracterização da bebida láctea pasteurizada com adição de ferro foi realizada mediante análises físico-químicas e microbiológicas. Também foi realizada uma avaliação qualitativa das matérias-primas utilizadas em seu preparo. Todas as análises foram realizadas no laboratório de qualidade do estabelecimento Laticínios P \& F de Valença Ltda.

\section{Elaboração da bebida}

Para a elaboração da bebida láctea com adição de ferro são necessários cuidados antes de seu preparo, sendo a avaliação qualitativa das matérias-primas 
muito importante para a obtenção de um produto de qualidade.

Foram realizadas duas análises rotineiras nesses produtos: acidez em graus Dornic e $\mathrm{pH}$. O soro de leite foi obtido do processo de fabricação de queijo minas frescal, para então sofrer o processo de pasteurização a $80{ }^{\circ} \mathrm{C}$, durante 18 segundos, e resfriado a $2^{\circ} \mathrm{C}$. O leite cru transportado a granel de cooperativas da região ao Laticínio passou pelo processo de pasteurização rápida (a $75^{\circ} \mathrm{C}$, durante 18 segundos), e resfriado a $2^{\circ} \mathrm{C}$. O creme de leite utilizado foi elaborado com o leite pasteurizado, para somente então a bebida ser elaborada.

O gráfico 1 representa a formulação da bebida com suas respectivas concentrações.

Gráfíco 1. Composição da bebida láctea pasteurizada com adição de Ferro.

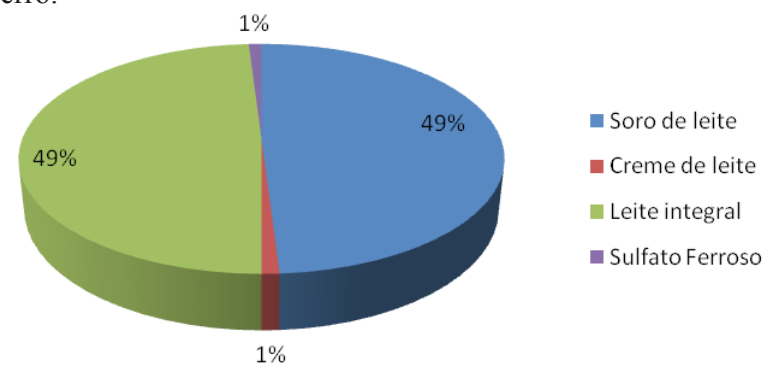

O leite integral e o soro de leite foram encaminhados do tanque de armazenagem para o tanque balão onde a bebida é preparada. Adicionaram-se o creme de leite e o sulfato ferroso. O preparo da bebida foi realizado à temperatura de $3^{\circ} \mathrm{C}$, resultando em um produto com características sensoriais de consistência líquida, cor branca, odor e sabor característicos de leite integral, pois não há adição de nenhum corante, aromatizante ou quaisquer outras substâncias que ocasionassem alterações.

\section{Caracterização físico-química}

As análises físico-químicas da bebida elaborada constituíram-se de acidez, $\mathrm{pH}$, lipídeos, densidade, proteínas, cinzas, carboidratos, umidade, extrato seco total (\%EST) e extrato seco desengordurado (\%ESD). Todas as análises foram realizadas de acordo com os métodos analíticos da Association of official Analytical Chemists - AOAC (2005) e do Instituto Adolfo Lutz (2008). Os resultados foram analisados segundo a legislação vigente para bebida láctea [Brasil 2005] e comparados com os encontrados por Farias et Al. [2006].

A acidez titulável foi realizada pelo método "Acidez titulável para leite fluido em solução Dornic": em $10 \mathrm{ml}$ de amostra adicionaram-se 3 gotas de fenolftaleína. Em seguida titulou-se com solução de hidróxido de sódio 1/9M, em acidímetro Dornic.
$\mathrm{O} \mathrm{pH}$ foi determinado pelo método do uso de pHmetro. O aparelho foi calibrado com solução tampão de pH 4,7 e 10 e, em seguida, foi feita a medição da amostra.

A determinação lipídica foi realizada pelo método Butirométrico para leite fluído: em 1 frasco butirômetro adicionaram-se $10 \mathrm{ml}$ de ácido sulfúrico concentrado. Em seguida adicionaram-se $11 \mathrm{ml}$ da amostra lentamente e 1 $\mathrm{ml}$ de álcool isoamílico e centrifuga-se a $1000 \mathrm{rpm}$, por 5 minutos.

A análise de proteína foi realizada pelo método de digestão Kjeldahl, utilizando o fator de correção de 6,38 para leite e derivados.

A determinação da umidade foi realizada em aparelho analisador de umidade por infravermelho.

A densidade a $15^{\circ} \mathrm{C}$ foi calculada pelo método do Termolactodensímetro. Após a medição no termolactodensímetro fez-se a correção da densidade pela temperatura através de tabela.

O Extrato seco total foi calculado por meio do método disco de Ackermann. Para verificar o valor do extrato seco total pelo disco de Ackermann fez-se coincidir as graduações dos círculos interno e médio, correspondentes à densidade e a gordura, respectivamente. A posição da flecha indica, no circulo externo, o extrato seco total por cento $\mathrm{m} / \mathrm{v}(\% \mathrm{EST})$.

O Extrato seco desengordurado foi calculado de acordo com a fórmula abaixo (Onde P é o número de grama do extrato seco total $(\mathrm{m} / \mathrm{v})$, e $\mathrm{G}$ é o número de grama de gordura por cento $(\mathrm{m} / \mathrm{v}))$ :

\section{$D-G=$ Extrato seco desengordurado}

Para a determinação de resíduos por incineração (Cinzas), a amostra foi evaporada em banho-maria, carbonizada e, em seguida, calcinada em mufla a 450 ${ }^{\circ} \mathrm{C}$ até peso constante.

O valor calórico foi determinado conforme a equação a seguir:

Valor calórico $=\left(\right.$ proteina $\left.X_{4}\right)+\left(\right.$ carboidratos $\left.X_{4}\right)+\left(\right.$ gordura $\left.X_{9}\right)$

Para a determinação de carboidratos utilizou-se da somatória dos teores de proteína, gordura, umidade e cinzas, de acordo com a equação a seguir:

Carboidrato $=100-$ (proteina + gordura + umidade + cinzas $)$

\section{Caracterização microbiológica}

As análises microbiológicas de contagem de coliformes totais a $30^{\circ} \mathrm{C}$ e aeróbios mesófilos foram realizadas em triplicata, seguindo o método descrito por Brasil (2003). Os resultados foram analisados e comparados segundo a legislação vigente [Brasil 2005].

Para análise de mesófilos aeróbios foram utilizadas diluições da amostra com solução salina peptonada $0,1 \%$. 
Cerca de $1 \mathrm{ml}$ de cada diluição selecionada foi semeada em placas de Petri estéreis. Em seguida adicionou-se o caldo verde (Agar padrão para contagem - PCA), e a solução foi homogeneizada e deixada em descanso até solidificar, para então incubar as placas invertidas a $36^{\circ} \mathrm{C}$, por 48 horas.

Para a determinação de Coliformes Totais utilizouse o mesmo método descrito acima, substituindo o caldo verde por VRBA (Ágar cristal violeta vermelho neutro bile). A incubação foi realizada a $36^{\circ} \mathrm{C}$, por 24 horas.

\section{Resultados e Discussões}

Com o aumento na comercialização dos produtos lácteos há um aumento no número de pesquisas sobre a sua qualidade, o que reflete uma maior preocupação com a inocuidade do alimento [Thamer e Penna 2006]. Por esse motivo, para a obtenção de um produto de qualidade, é necessário, antes de seu preparo, um exímio controle da qualidade de suas matérias-primas.

$\mathrm{Na}$ Tabela 1, observa-se os resultados das principais análises realizadas com os ingredientes da formulação da bebida láctea pasteurizada com adição de sulfato ferroso.

Tabela 1. Análises dos constituintes da bebida láctea.

\begin{tabular}{cccc}
\hline Análises & Soro & Leite & Creme \\
\hline Acidez & $11,3 \pm 0,4082$ & $16,8 \pm 0,2041$ & $18,3 \pm 0,4301$ \\
\hline $\mathrm{pH}$ & $6,2 \pm 0,0442$ & $6,8 \pm 0,0707$ & $7,2 \pm 0,0286$ \\
\hline
\end{tabular}

Fonte. Arquivo pessoal

Segundo a legislação vigente para soro de leite, leite integral e creme de leite, o valor mínimo estipulado para a acidez do soro doce é de $0,10 \%\left(10^{\circ} \mathrm{D}\right)$ e o máximo é de $0,14 \%\left(14^{\circ} \mathrm{D}\right)$, sendo o $\mathrm{pH}$ de 6,0 a 6,8 [Brasil 1999]. Para o leite pasteurizado, a acidez preconizada é de $0,15 \%\left(15^{\circ} \mathrm{D}\right)$ a $0,18 \%\left(18^{\circ} \mathrm{D}\right)$ [Brasil 2002]. Já em relação ao creme de leite, a acidez deve ser de, no máximo, 0,20\% (20ㄱ) [Brasil 1996]. Dessa forma, os resultados obtidos no presente trabalho para $\mathrm{pH}$ e acidez do soro e acidez do leite e do creme de leite estão dentro do estipulado pela legislação vigente.

A concentração de sulfato ferroso adicionada à bebida láctea produzida nos Laticínios $\mathrm{P} \& \mathrm{~F}$ de Valença Ltda foi de $2,5 \mathrm{mg} / 100 \mathrm{ml}$. Para que uma bebida Láctea seja considerada como alimento enriquecido ou fortificado é necessário que seja constituída de um ou mais nutrientes essenciais, e que forneça no mínimo $60 \%$ da IDR (Ingestão Diária Recomendável) [Brasil 1978]. Uma vez que a IDR de ferro é de $27 \mathrm{mg}$ para gestantes, $15 \mathrm{mg}$ para lactantes, $14 \mathrm{mg}$ para adultos, $10 \mathrm{mg}$ para crianças de 7 a 10 anos, e 6 mg para crianças de 1 a 6 anos [Brasil 2005b], pode-se afirmar que a bebida láctea produzida no presente trabalho possibilita um fornecimento parcial da necessidade diária de ingestão desse nutriente.
A grande questão a respeito da adição de ferro a leites e derivados está na biodisponibilidade deste mineral, que é influenciada por fatores inibidores e facilitadores. Grandes concentrações de sulfato ferroso podem acarretar problemas sensoriais, tais como escurecimento, odor e sabor desagradáveis. Wang e King (1973) demonstraram que, com o uso de sais de ferro, o sabor oxidado no leite é intensificado. Segundo Douglas et al. (1981), isto ocorre devido a efeitos catalíticos do ferro na oxidação da gordura do leite. Nesse tipo de alimento, a fonte de ferro mais vantajosa, no sentido de não modificar as características sensoriais, é na forma de quelato, por apresentar maior estabilidade [Ashmead 1994]. A desvantagem da sua utilização é o maior custo ao fabricante, o qual será repassado ao consumidor, encarecendo o preço final do produto.

\section{Análises físico-químicas}

A legislação vigente no Brasil para bebidas lácteas é a Instrução Normativa n. ${ }^{\circ}$ 16, de 23 de agosto de 2005, a qual não apresenta nenhuma regulamentação para outras análises físico-químicas, a não ser para a que afere o teor de lipídios. A Instrução Normativa n ${ }^{\circ} 62$, de 29 de dezembro de 2011, para o controle de qualidade do leite pasteurizado, apresenta toda a regulamentação necessária para o controle físico, químico e microbiológico do mesmo.

Na tabela 2 estão os resultados encontrados para as análises físico-químicas da bebida preparada. Os resultados foram comparados com aqueles determinados pela legislação vigente para bebida láctea pasteurizada e para leite pasteurizado integral [Brasil 2005] e aos resultados encontrados por Farias et al. (2006), para a bebida láctea pasteurizada com adição de fruta (goiaba).

Tabela 2. Análises físico-químicas.

\begin{tabular}{|c|c|c|c|}
\hline Análises & $\begin{array}{l}\text { B e b i d a } \\
\text { láctea }\end{array}$ & $\begin{array}{c}\text { Farias et } \\
\text { al. [2006] }\end{array}$ & $\begin{array}{c}\text { Brasil } \\
\text { [2005] }\end{array}$ \\
\hline Acidez $\left[{ }^{\circ} \mathrm{D}\right]$ & $12,67 \pm 0,4082$ & $21[0,21 \%]$ & - \\
\hline $\begin{array}{c}\text { C a I o r i a s } \\
{[\mathrm{Kcal} / 100 \mathrm{~g}]}\end{array}$ & $90,04 \pm 1,4161$ & 86,42 & - \\
\hline Carboidratos [\%] & $16,70 \pm 0,4277$ & 18,97 & \\
\hline Cinzas [\%] & $0,38 \pm 0,0206$ & 0,49 & \\
\hline $\begin{array}{c}\text { De n s id a d e } \\
{\left[15^{\circ} \mathrm{C}\right]}\end{array}$ & 1025 & - & - \\
\hline$\%$ EST & $9,22 \pm 0,0490$ & - & \\
\hline$\%$ ESD & $7,15 \pm 0,0082$ & - & - \\
\hline Lipídeos [g/100g] & $2,07 \pm 0,0408$ & 1,46 & 2,0 \\
\hline Proteínas [\%] & $1,16 \pm 0,04167$ & 0,60 & 1,0 \\
\hline $\mathrm{pH}$ & 6,53 & 4,46 & - \\
\hline Umidade [\%] & $79,69 \pm 0,2858$ & 73,48 & - \\
\hline Temperatura $\left[{ }^{\circ} \mathrm{C}\right]$ & 4 & - & Máx. 4 \\
\hline
\end{tabular}

Fonte. Arquivo pessoal 
A temperatura da bebida láctea adicionada ao ferro no momento da análise foi a mesma utilizada no momento da sua elaboração. Em Brasil (2005) a temperatura de preparo para a bebida láctea deve ser de no máximo $4^{\circ} \mathrm{C}$ e, após o envase, a estocagem deve ser feita a temperatura de até $7^{\circ} \mathrm{C}$.

Observou-se que, com relação à acidez titulável, a bebida láctea com ferro obteve um valor abaixo do encontrado por Farias et al. (2006) obtendo-se um pH mais elevado. Provavelmente, esse resultado ocorreu porque a bebida elaborada por Farias et al. (2006) era composta por frutas, e a produzida no presente trabalho tem adição apenas de sulfato ferroso, o qual não contribuiu para acidificação do meio. A legislação vigente não estabelece o valor da acidez para bebida láctea, pasteurizada ou não. Desse modo, considerando que $49 \%$ da bebida formulada é composta por soro de leite e que não leva em sua formulação nenhuma substância para corrigir a acidez e o $\mathrm{pH}$, podemos considerar que o resultado para a acidez está em um padrão aceitável.

A concentração de lipídeos observada na bebida elaborada no presente trabalho apresentou-se em maior quantidade quando comparada à encontrada por Farias et al. (2006). A legislação vigente [Brasil 2005] para bebida láctea pasteurizada com adição, no entanto, considera ideal uma concentração lipídica de no mínimo $2 \%$, o que corrobora com o resultado encontrado na bebida láctea com adição de ferro.

A densidade depende da quantidade de gordura e de sólidos não gordurosos, pois a gordura do leite tem uma densidade menor que a da água, enquanto que os sólidos não gordurosos têm uma densidade maior. Isso explica a baixa densidade encontrada para a bebida em questão e, consequentemente, os valores correspondentes para os percentuais de extrato seco total e extrato seco desengordurado.

A umidade dos alimentos está relacionada com a sua estabilidade, qualidade e composição. A umidade da bebida com ferro apresentou um valor de 79,69\%, uma vez que é elaborada basicamente com leite fluido e soro, e que em torno de $93 \%$ do soro e $88 \%$ do leite são constituídos por água, o que explica o resultado encontrado.

O teor de proteínas encontrado na bebida com ferro está dentro do permitido pela legislação [Brasil 2005] que determina que o teor proteico para bebida láctea pasteurizada com adição, deve ser de, no mínimo, 1\%. $\mathrm{O}$ valor encontrado por Farias et al. (2006) corresponde a quase metade ao encontrado na bebida com ferro. No entanto, o teor de carboidratos encontrado pelo mesmo autor foi acima do encontrado para a bebida com ferro, provavelmente pelo fato da bebida elaborada por Farias et al. (2006) ter adição de polpa de fruta (goiaba), o que também afetou o teor de cinzas, que foi menor na bebida com ferro. Ainda se tratando de fatores nutricionais, a bebida com ferro apresentou um valor calórico maior do que a elaborada por Farias et al. (2006), resultado explicado pelo fato de a bebida com ferro ter uma concentração maior de lipídios e proteínas.

\section{Análises Microbiológicas}

A Tabela 3 apresenta os resultados para as análises microbiológicas exigidas pela legislação vigente [Brasil 2005].

Tabela 3. Análises microbiológicas.

\begin{tabular}{ccc}
\hline Análises & Bebida láctea & Brasil [2005] \\
\hline Mesófilos $[/ \mathrm{g}]$ & $1,0 \times 102$ & $1,5 \times 105$ \\
\hline Coliformes $\left[30^{\circ} \mathrm{C}\right][/ \mathrm{g}]$ & $<3$ & $<10$ \\
\hline
\end{tabular}

Fonte. Arquivo pessoal

Os resultados para as análises microbiológicas de mesófilos e coliformes totais $\left(30^{\circ} \mathrm{C}\right)$ encontram-se dentro do recomendado por Brasil (2005). Isso prova que os cuidados durante o processo de fabricação, como limpeza dos equipamentos e utensílios, higiene dos trabalhadores e do local de preparo, bem como cuidado em relação à qualidade das matérias-primas utilizadas são muito importantes para a obtenção de um produto inócuo e isento de riscos para o consumidor.

\section{Conclusão}

A bebida láctea pasteurizada com adição de ferro analisada apresentou resultados, em sua caracterização físico-química e microbiológica, que comprovam a qualidade do alimento. Os resultados para os parâmetros de qualidade exigidos por Brasil (2005), tais como lipídeos, proteínas, coliformes totais e mesofilos encontram-se dentro das recomendações estabelecidas.

Embora a concentração de ferro na bebida láctea elaborada no presente trabalho $(2,5 \mathrm{mg} / 100 \mathrm{ml})$ não permita classificá-la como alimento enriquecido, a fonte de ferro utilizada permite chegar a um nível que torna esse alimento uma boa opção como complemento parcial à Ingestão Diária Recomendável (IDR) de ferro, sem tornar a formulação onerosa demais aos fabricantes, uma vez que o sulfato ferroso é uma opção de menor custo.

O sulfato ferroso na concentração utilizada para a elaboração da bebida láctea, não alterou suas características sensoriais. No entanto, para se considerar a bebida láctea como alimento enriquecido em ferro, seria necessária uma maior concentração do sulfato ferroso, o que comprometeria seu aspecto sensorial. Uma alternativa é utilizar compostos de ferro quelados. No entanto, essas formas elevariam o custo da formulação. Com a quantidade de sulfato ferroso utilizada no presente trabalho, foi possível elaborar uma bebida láctea sem prejuízos ao aspecto sensorial e com baixo custo, resultando em um produto que supriria parcialmente as necessidades desse elemento. 


\section{Referências}

Almeida, K. E.; Bonassi, I. A.; Roça, R. O. (2001). Características físicas e químicas de bebidas lácteas fermentadas e preparadas com soro de queijo minas frescal. Ciência e Tecnologia de Alimentos, v.21, pp.187-192.

Ashmead, H. DeWayne, RAPP, E. J., Name, J. J. (1994). Uso de aminoácidos quelato na fortificação de alimentos. IN: Seminário Brasileiro de Alimentos enriquecidos, Campinas: Ital, UNICAMP, pp. 32-37.

Bhemer. Arruda M. L. (1999). Tecnologia do Leite-produção industrialização e análise. 13. ${ }^{\mathrm{a}}$ ed. São Paulo: Nobel.

Brasil, Ministério de Estado da Agricultura, Pecuária e Abastecimento. (2003). Instrução Normativa $n^{\circ}$ 62, de 26 de agosto de 2003. Anexo I. Métodos Analíticos Oficiais para Análises Microbiológicas para Controle de Produtos de Origem Animal e Água.

Brasil, Ministério de Estado da Agricultura, Pecuária e Abastecimento. (2005). Instrução Normativa n. ${ }^{\circ} 16$, de 23 de agosto de 2005. Regulamento Técnico de Identidade e Qualidade de Bebidas Láctea.

Brasil, Agência Nacional de Vigilância Sanitária. (2005b). RDC n. ${ }^{\circ} 269$, de 22 de setembro de 2005. Regulamento Técnico sobre ingestão Diária Recomendada (IDR) de Proteína, Vitaminas e Minerais. Brasília, DF.

Brasil, Ministério da Saúde. (1978). Resolução 12/78 do CNNPA. Legislação de Alimentos. Diário oficial da Republica Federativa do Brasil, Brasília, 24 de julho de 1978 .

Brasil, Ministério de Estado da Agricultura, Pecuária e Abastecimento. (1999). Instrução Normativa n. ${ }^{\circ} 3$, de 22 de janeiro de 1999. Regulamento Técnico de Identidade e Qualidade de Soro de Leite.

Brasil, Ministério de Estado da Agricultura, Pecuária e Abastecimento. (2002). Instrução Normativa n. ${ }^{\circ} .51$, de 18 de setembro de 2002. Regulamento Técnico de Produção, Identidade e Qualidade de Leite Tipo A.

Brasil, Ministério de Estado da Agricultura, Pecuária e Abastecimento. (1996). Portaria n. ${ }^{\circ} 146$, de 7 de março de 1996. Regulamento Técnico de Identidade e Qualidade de Creme de Leite.

Bem-Hassan, R. M.; Ghaly, A. E., (1994). Continuous propagation of Kluyveromyces fragilis in cheese whey for pollution potential reduction. Applied Biochemistry and Biotechnology, v.47, pp. 89-105.

Cook, J.D.; Baynes, R. D.; Skikne BS. (1992). Iron deficiency and the measurement of iron status. Nutr Res Ver 5: pp. 189-202.

Cook, J. D.; Reusser, E. M. (1983). Iron fortification: an update. IN: The American Journal of Clinical Nutrition. Disponível em: http://www.ajcn.org/ content/38/4/648 Acesso em: 23/05/12.

Carmo, L. S. (2001). Produção e purificação em grande escala das enterotoxinas estafilocócicas.

Douglas, F. W. JR., Rainey, N. H., Wong, N. P., Edmondson, L. F., Lacroix, D. E. (1981). Color, flavor, and iron bioavailability in iron-fortified chocolate milk. J. Dairy Sci. v. 64, n. ${ }^{\circ}$ 9, pp.1785-1793.

Farias, F.C.; Lima, L.D.S. (2006). Elaboração de bebida pasteurizada a partir do soro do leite bovino com características funcionais e sabor fruta regional. Universidade do Estado do Pará, Paragominas, 58p.

FAO, Food and Agriculture Organization of the United Nations, (2007).

Ghaly, A. E.; Kamal, M. A. (2004). Submerged yeast fermentation of acid cheese whey for protein production and pollution potential reduction. Water Research, v. 38, pp.631-644

Instituto Adolfo Lutz (2008). Normas Analíticas do Instituto Adolfo Lutz: Métodos químicos e físicos para análise de alimentos, edição IV. 1. ${ }^{a}$ edição digital. São Paulo: IMESP, 2008.

Mawson, A. J. (1994). Bioconversions for whey utilization and waste abatement. Bioresource Technology, v.47, n. ${ }^{\circ} 3$, pp. 195-203.

Mosquim, M. C. A.V. (1996). Propriedades Funcionais do soro de queijo. In: Encontro digital de Tecnologia de Laticínios, Viçosa, MG.
Association of Official Analytical Chemists - AOAC. Official Methods of Analysis, Washington, 16. ${ }^{\mathrm{a}}$ ed., 1995.

Organização Mundial de Saúde (1972). Anemias nutricionais. Genebra. Série de Informes Técnicos, 456.

Pereira Jr. F. N.; Fonseca, L. M.; Soares, F. M.; Sá, M. J. S.; Machado, E.C.; Amado, J. E. S. (2001). Comparação de métodos de enumeração de estimativa de microrganismos psicrotróficos em leite cru e avaliação do teste Moseley. Revista UFMG. pp. 14-32.

Pintado, M. E. et al. (2001). Review: technology, chemistry and microbiology of whey cheeses. Food Science Technology International, v.7, n.2, p.105116.

Queiroz, S. S. (2001). O papel do ferro na alimentação infantil. Nestlé, Temas de nutrição em Pediatria, v. 1, pp. 7-12.

Richards, N. S. P.S. (1997). Emprego racional do soro láctico. Indústria de Laticínios. maio/junho, pp. 67-69.

Santos, C. T. et al. (2008). Influência da concentração de soro na aceitação sensorial de bebida láctea fermentada com polpa de manga. Alimentos e nutrição, v. 19, n. ${ }^{\circ} 1$, pp. 55-60, Dispnível em http://200.145.71.150/seer/ index.php/alimentos/article/viewFile/199/204 Acesso em 09/06/12.

Simionato, J. I. (2008). Composição química e quantificação de ácidos graxos com ênfase ao acido linoleico conjugado (CLA) em leite e derivados. Universidade Estadual de Maringá, Maringá, PR, p. 123.

Siso, M. I. G., (1996). The biological utilization of cheese whey: a review. Bioresource Technology, v.57,p.1-11.

Thamer, K. G.; Penna, A. L. B. (2006). Caracterização de bebidas lácteas funcionais fermentadas por probióticos e acrescidas de prebiótico. Ciência e tecnologia de alimentos. Campinas, v.26, n. ${ }^{\circ} 3$, pp. 589-595.

Torres, M. A. A.; Lobo, N. F.; Sato, K.; Souza Queiroz, S. (1996). Fortificação do leite fluido na prevenção e tratamento da anemia carencial ferropriva em crianças menores de 4 anos. Revista de Saúde Pública, v. 30.

Wang, C. F., King, R. L. (1973). Chemical and sensory evaluation of iron fortified milk. J. Food Sci., v. 38, n.6, pp.938-940.

\section{Agradecimentos}

Os autores agradecem ao Laticínios P \& F de Valença Ltda., que gentilmente cedeu a estrutura do laboratório para a realização desta pesquisa. 